\title{
A MULHER QUE É HISTÓRIA: ESBOÇOS SOBRE O SEPULTAMENTO DE IYÁ STELLA DE OXOSSI
}

\author{
Iyáromi Feitosa Ahualli ${ }^{1}$ \\ Silvana Gorete Estevam de Almeida ${ }^{2}$ \\ DOI 10.26512/revistacalundu.v4i1.30794
}

Este texto tem como finalidade esboçar, de forma ensaística, questões sobre a forma que o sistema de justiça brasileiro vem lidando com as demandas das comunidades tradicionais, em especial, sobre o caso que envolveu o sepultamento de Iyá Stella de Oxossi.

\section{Stella para o mundo}

Maria Stella de Azevedo. Mulher, negra, brasileira, nordestina, candomblecista, descendente de negros da etnia Egba, que foram trazidos para o Brasil sob a condição do contexto da diáspora. Quarta filha do casal Esmeraldo Antigno dos Santos e Thomazia Azevedo Santos, chega à religião dos orixás levada por sua tia, que lhe entrega aos cuidados de Mãe Senhora (Maria Bibiana do Espirito Santo) então Iyálorixá do Terreiro Ilê Asé Opo Afonjá (Salvador/BA). Mãe Stella concluiu seus estudos ao longo dos anos formando-se pela escola de enfermagem e saúde pública, exercendo a função de visitadora sanitária por mais de 30 anos, porém não deixando de lado em nenhum momento sequer os seus compromissos religiosos. No dia 19 de março de 1976, 1 ano depois do falecimento de Mãezinha (Mãe Ondina de Oxalá) ${ }^{3}$, e cumpridas todas as cerimônias fúnebres em honra da falecida, Mãe Stella é escolhida como a $5^{\text {a }}$ Iyálorixá do Axé Opo Afonjá, através de jogo divinatório realizado pelo Professor e Babalaô Agenor Miranda, na presença de toda comunidade religiosa desse terreiro e de outras casas, que aguardavam pelos desígnios de Xangô, orixá patrono do terreiro.

\footnotetext{
1 Antropóloga formada pela Universidade de Brasília - UnB; Graduanda em Direito pelo Centro Comunitário de Brasília - UniCEUB. Integrante do Grupo Calundu. E-mail: ifahualli@gmail.com

${ }^{2}$ Gestora em Salvaguarda do Património Cultural dos Povos de Terreiros pela Universidade Federal da Bahia- UFBA; graduanda em Direito pelo Centro Universitário da Bahia - Estácio FIB; Graduanda em Museologia pela Universidade Federal da Bahia-UFBA. E-mail: sgestevam@gmail.com

${ }^{3}$ ERRATA: A pedido das autoras, houve neste trecho uma alteração do texto, após sua publicação. A versão originalmente publicada trazia o nome da mãe de santo Mãe Senhora como antecessora direta de Iyá Stella. Por ter sido a informação corrigida pelas autoras, com posterior pedido de troca do texto publicado, segue nesta versão, corrigida, esta errata.
} 
A partir desse momento a vida passa a ser completamente diferente: gerir uma casa com tantas histórias, com tantas filhas/os, preceitos e tradições não seria tarefa fácil, contudo, aos poucos, foi se adaptando à nova condição e então começa a luta de Mãe Stella, a qual tivemos a honra de conhecer ou no mínimo ouvir falar.

$\mathrm{Na}$ década de 80, sua busca pelas raízes familiares e religiosas a leva até o continente africano por diversas ocasiões e, sendo recebida com honras de líder religiosa, participa também de eventos e conferências internacionais ligadas ao culto de orixás, publica seu primeiro livro em parceria com (a Advogada e) sua filha de santo Cléo Martins, a quem conferiu o cargo de Agbeni Xangô e que foi sua parceira em diversas outras publicações ao longo da vida. Na década de 90, assiste ao tombamento do terreiro do Opo Afonjá, que tinha demandado ao Instituto do Patrimônio Histórico Artístico Nacional - IPHAN.

O encantamento pelas palavras, pela transmissão de sabedoria, pela educação, a fez criar a escola Ana Eugenia dos Santos, primeira escola dentro de terreiro, e primeira a ter entre seus componentes curriculares o ensino de línguas e culturas africanas. Conseguiu realizar um belíssimo projeto, que foi o ônibus biblioteca, que rodava a cidade de Salvador oferecendo às comunidades carentes o acesso à literatura, cultura, educação e etc. Esse mesmo fascínio a impulsionou a escrever diversas vezes na coluna "Opinião", veiculada por um longo tempo num jornal de grande circulação de Salvador. Durante sua vida acumulou diversos títulos e honrarias, entre elas, doutora honoris causa pela Universidade Federal da Bahia, e em setembro de 2013 foi escolhida para ocupar a cadeira 33 da Academia Baiana de Letras, que tem como patrono o poeta Castro Alves.

Maria Stella de Azevedo: uma mulher à frente de seu tempo, que deixou um enorme legado não só para as comunidades praticantes da religião de matriz africana, bem como para o mundo. Falava de preservação ambiental, dignidade da pessoa humana, liberdade de culto, pacificação, respeito à cultura e tradição de povos, história, memória, patrimônio material e imaterial, respeitada por artistas, políticos, sociedade civil organizada, órgãos públicos, indivíduos de todas as classes sociais.

\section{Do Aye ao Orun ${ }^{4}$}

No fim de 2017, por questões pessoais, que não cabe prolongar em respeito à sua memória e de sua família, Mãe Stella sai de sua casa, dentro do terreiro Opo Afonjá,

\footnotetext{
${ }^{4}$ Aye para a cultura yorubana representa a terra; e Orun o céu.
} 
para ir morar com sua companheira na cidade de Nazaré das Farinhas, recôncavo baiano. A mudança foi cercada por diversas questões: familiares, legais, religiosas que a levaram a desgastes físicos, psíquicos, emocionais e de imagem, culminando com sua morte na tarde do dia 27/12/2018, na cidade supracitada, decorrente de diversas internações por problemas respiratórios e cardíacos - uma tarde que jamais será esquecida, nem pelas filhas do Terreiro Opô Afonjá, nem pelo Brasil.

Notícias desencontradas, um misto de tristeza, emoção e desespero toma conta da comunidade do Opo Afonjá, da comunidade religiosa e do povo em geral. Nos terreiros, nos grupos de WhatsApp, nas esquinas, nas casas, toda Salvador parava diante de qualquer notícia para saber de fato se era verdade o que ouviam. Uma mulher guerreira, revolucionária, integrante da academia Baiana de letras, Iyálorixá, militante, enfermeira, intelectual, entre outras tantas qualidades as quais seria incapaz de dizê-las todas.

O falecimento de Iyá Stella fez girar uma polêmica que, apesar de não ser contemporânea, ganhou visibilidade por envolver essa persona significativa para história das comunidades de terreiro. Como dito acima, na data de seu falecimento, Iyá Stella se encontrava fora de Salvador, morando junto com sua companheira. O que nos interessa é que no meio deste conflito, o corpo de Iyá Stella estaria fora da cidade de Salvador-BH, longe da família, amigas, filhas de santo, de seus orixás, do seu terreiro, sendo velada como uma pessoa não iniciada, sem nenhum reconhecimento de seu cargo religioso, considerado o cargo de uma realeza dentro das comunidades afro-ameríndias religiosas, distante da comunidade que liderou durante 43 anos, quase meio século. Nesse momento, seu sobrinho Adriano de Azevedo Santos Filho, Obá Abiodun, um dos ministros que compõem a Corte de Xangô do Opo Afonja ${ }^{5}$, começa a tentar solucionar o conflito do enterro, junto com outros integrantes da Corte de Xangô do terreiro. E é o desenrolar desses momentos conflituosos que embarcaram nossas considerações.

\section{Xangô $\hat{0}^{6}$ abre o rito fúnebre}

Iyá Stella lutava e era militante ativa das religiões afro-ameríndias desde seus primeiros passos no terreiro que foi também sua casa. A luta contra o racismo religioso e a favor da realização de todos os ritos que compõem a cosmologia do candomblé não

\footnotetext{
${ }^{5}$ A Corte de Xangô é um título honorífico que compõe um corpo político. Este corpo, formado por ministros escolhidos por ritos específicos, tem voz de decisão na comunidade à qual pertencem.

${ }^{6}$ Xangô, para a afrorreligiosidade yorubana, é o Orixá, a força da justiça. O rei.
} 
é uma luta recente, tão pouco abafada pelo tempo. Antes dos conflitos começarem a surgir em seu caminho, segundo informantes do axé $e^{7}$, Iyá Stella já havia declarado, inclusive na presença de testemunhas, as orientações necessárias para a futura ocasião da realização de seu rito fúnebre. Isso porque, na concepção das religiões afroameríndias, o evento "morte" é considerado uma mudança de estado, uma alocação de função da iniciada dentro da cosmologia, ou seja, a iniciada transpassa a sua posição hierárquica na presença material e passa, muitas vezes, ao cargo de ancestral.

Diante de tal cenário, surge uma verdadeira batalha, primeiro contra o tempo, depois a legal, pois o corpo estava na posse de sua companheira e tutora, com a qual conviveu durante o período em que esteve fora do terreiro. Começa então um litígio jurídico, entre aquilo que se pode objetivar como um direito familiar e algo que vai mais além, e que perpassa pela concepção de direitos coletivos e laicidade estatal.

No âmbito do direito, baseado nas teorias de Mir Puig (2011), que trata os objetos reais da tutela em suas realidades materiais ou imateriais, a expressão da dimensão social, de forma que sua plenitude represente "uma necessidade social" e condicione "as possibilidades de participação do indivíduo nos sistemas sociais". O bem jurídico radicaria em uma realidade empírica, que seria substrato material do bem jurídico. Para Mir Puig, "o conceito de bem jurídico seria a expressão de uma relação dialética de realidade e valor".

Apesar do conceito de bem jurídico ter sido forjado no plano normativo (valorativo), apresenta um referencial material (antológico) conectado à realidade existencial (material ou imaterial). Esse tipo de filtro valorativo seria responsável pela “seleção dos concretos elementos, dados, interesses ou relações extraídas à luz de um determinado momento histórico poderá ensejar em um recurso de tutela penal (subsidiária).”. A concepções de bens jurídicos, tutela a concepção do rito fúnebre religioso como um bem jurídico ao ponto de torna-lo digno de uma garantia.

A laicidade do Estado é uma questão base para a situação, que apesar de muito bem desenvolvida por autoras como Ariadne Moreira Basílio de Oliveira (2018) , Andréa Letícia Carvalho Guimarães (2018) e Nilo Sérgio Nogueira, ainda tem muito a ser explorada. Laicidade não abarca somente a questão da separação entre o Estado e as religiões, está muito além disso. $\mathrm{Na}$ perspectiva jurídica, ela deve garantir a independência e igualdade para todas as religiões, e o Estado, constituído a partir da

\footnotetext{
${ }^{7}$ Por respeito à conservação da imagem e do cargo, a pessoa que nos passou a informação, inclusive com provas, pediu para não ser revelada a sua identidade.
} 
Constituição Federal Brasileira de 88, não pode interferir de forma a defender exclusivamente uma das religiões, o dever do Estado é garantir que todas tenham os mesmos direitos, e que a aplicabilidade da lei seja garantida de maneira equânime. Para além disso, falar de laicidade é também e principalmente falar de um reconhecimento de cidadania.

\section{E o corpo, quem tem direito?}

A Sociedade Cruz Santa do Opo Afonjá, entidade civil, com registro e estatuto, constituída de poderes legais, entra com uma ação para solicitar que o corpo de Mãe Stella seja devolvido ao terreiro para que possam ser prestadas as devidas honrarias e para que possam ser feitos os rituais de sua religião.

Era preciso garantir à comunidade o direito de poder velar, enterrar, e cultuar seu ente, que pelo fato de não estar mais entre os vivos, não poderia solicitar que fosse feito aquilo que preconizou em vida, e que estava sendo impedido por um direito que, embora fosse legalmente válido, não poderia se sobrepor a algo muito maior, e que tinha abrangência e importância sobre a vida de diversas pessoas no país, e mesmo que não o fosse, pois fazia-se necessário garantir o princípio da dignidade da pessoa humana, que protege o indivíduo não somente em sua existência física, bem como depois dela, vide Capítulo 1 da Constituição Federativa do Brasil.

O princípio da dignidade da pessoa humana não se extingue com a vida e os indivíduos não perdem a personalidade histórica perante as suas comunidades. Principalmente quando se trata do candomblé, para as religiões de matrizes africanas, os seus antepassados permanecem aliados à comunidade como forma de proteção da mesma, de modo que, uma vez que tenham morrido fisicamente, ainda vivem e servem a comunidade como forma de proteção espiritual. Portanto, a sua imagem perante a comunidade à qual pertence deve ser preservada e os ritos praticados por essa comunidade devem ser respeitados e seguidos, sob pena de uma vez que não o sejam, a comunidade venha perder a sua identidade ou a tradição, o que é imprescindível para manutenção da unidade do grupo que, no caso em questão, é um patrimônio tombado pelo IPHAN, que reconheceu sua importância para a história e a memória do país.

Em contrapartida, a discussão jurídica perpassa primordialmente pelo Direito de Família, no que tange à tutela do corpo, observando as normas previstas na lei 9.434/97. Após a morte, no entanto, a autorização é exclusiva do cônjuge ou 
parente, maior de idade, obedecida a linha sucessória, reta ou colateral, até o segundo grau inclusive. O Supremo Tribunal de Justiça - mesmo sem qualquer previsão a respeito na legislação brasileira, mas valendo-se da analogia, dos costumes e princípios gerais do direito - institutos previstos no $4^{\circ}$ artigo da lei de Introdução às Normas do Direito Brasileiro, julgou procedente o pleito judicial que tutela o corpo do morto como respaldado na lei 9.434/97.

Para além da tutela do corpo pertencer à família que, no caso abordado, entrou em conflito quando de um lado teríamos a conjunge dela priorizando um velório sem os devidos ritos da religião à qual Iyá Stella para além de pertencer, era uma líder. E do outro lado temos as filhas e o sobrinho, juntamente ao Ilê Axé Opo Afonja, casa da qual ela era líder. Apesar deste contexto familiar conflituoso, temos como possível análise os cargos religiosos como representantes/tutores, enquanto atores dignos de reconhecimento jurídico, pelo menos no que tange a responsabilidade e realização dos ritos.

\section{O que aprendemos com o enterro de Iyá Stella?}

$\mathrm{O}$ rito de passagem para algumas religiões tem tanta importância quanto o nascimento; existe uma mística, uma interação entre a comunidade e seu morto que, no caso do candomblé, passa a integrar o corpo religioso, ancestral e identitário do grupo após a realização dos ritos litúrgicos elencados na tradição do culto. Nas religiões afroameríndias, a hierarquia ${ }^{8}$ é exaltada pela cosmologia da transmissão do conhecimento, entre outras características. Portanto, o conhecimento é passado da mais velha para a mais nova ${ }^{9}$. Ao escrever esse texto reflexivo, o primeiro questionamento é sobre qual foi a lição que Iyá Stella nos deixou nesse evento. Observa-se que houve um conflito de vontades entre a companheira de Iyá Stella e sua família de sangue e espiritual, o Ilê Axé Opo Afonjá. Para além de herança, o embate inicia-se no enterro de Iyá Stella, onde a parte de sua companheira antecipadamente velou o corpo de Iyá Stella em uma capela longe de seu terreiro e sem seguir os ritos afro-religiosos da comunidade à qual Iyá Stella pertencia e da qual era a Iyálorixá.

\footnotetext{
${ }^{8}$ DAMASIO, A. C. S.; AHUALLI, I. F. “Às Mais Velhas”. In: BRASÍLIA: Revista Calundu, v.2n.2, 2018 (http://periodicos.unb.br/index.php/revistacalundu/article/view/15261).

${ }^{9}$ Apesar do respeito à idade cronológica, o tempo de iniciação de uma pessoa é o marcador temporal usado para a construção da cadeia hierárquica nas religiões afro-ameríndias.
} 
O conflito chegou à Justiça Federal Brasileira, que precisou ser provocada para que fosse garantida a realização dos ritos de uma das Iyálorixás mais importantes do século XXI até então. E qual seria a relevância do rito para ser respaldado enquanto objeto jurídico? $\mathrm{Na}$ atual conjuntura política social, o reconhecimento jurídico da existência de um periculum in mora, correlacionado ao prejuízo que pode causar a "não realização do ritual religioso", importará no sepultamento da Iyá Stella de Oxossi, medida irreversível, periculum este que poria em risco a continuidade dos ritos religiosos da comunidade afro-ameríndia. A não realização do axexê (como um rito necessário para dar continuidade à comunidade), caracterizando-se enquanto periculum in mora, fortalece a importância dos ritos de nascimento e morte como bases necessárias na cosmologia do candomblé. Sem o axexê não há continuidade, sem o nascimento do Iyáwo também não.

Qual o periculum in mora defendido pela sentença? Uma diversidade de autores caracteriza os ritos afros fúnebres como manutenção necessária para a continuidade da comunidade. ${ }^{10}$ A importância dessa categoria tenciona o reconhecimento digno das Comunidades Tradicionais de Matriz Africana ${ }^{11}$ em tempos nos quais a política atual mostra-se permissiva à omissão a violências sofridas por esses povos. Há que se dizer que a busca pelo manejo da arbitrariedade jurídica, seja perante o reconhecimento de cidadania individualmente analisada, seja em grupo, perpassa pelas diversas formas de acesso e manejo dos instrumentos jurídicos-estatais. Mas será que essa porta foi aberta para as comunidades tradicionais ou só para Iyá Stella?

Eu acredito em Xangô, pois é um orixá justo e acredito também que um dia viveremos em harmonia porque o negro de terreiro, o negro de axé está tomando o seu lugar de direito, sem pisar em ninguém, se tornando (sic) advogados, juízes, publicitários, médicos e músicos, afirmando que a nossa cor e as nossas crenças não nos faz menores. Continuaremos existindo, como seres humanos que somos. Eu acredito em Xangô, eu acredito na Lei de Xangô (Adriano Santos Filho, Obá Abiodun) ${ }^{12}$.

\footnotetext{
${ }^{10}$ Luis Nicolau Pares (2016) caracteriza a necessidade de o rito fúnebre seguir seu preceito como forma de manutenção da vida social em tradições africanas, sendo a falta de sua execução uma quebra na construção identitária de um povo.

11 Definição legalmente reconhecida pelo decreto 6040/10. (http://www.planalto.gov.br/ccivil 03/ ato2007-2010/2007/decreto/d6040.htm)

12 Em entrevista.
} 


\section{É o fim?}

Indivíduos como Mãe Stella não morrem, continuam fazendo história e revoluções, pois para isso não é necessária a presença física diária, basta apenas plantar nos corações humanos ideias e bons pensamentos, pois estas não se apagarão jamais. Odé Kayodê, "O Caçador que traz alegria", deixa como herança de sua passagem pelo aye (mundo) a alegria e, como fiel representante de Xangô, o sentimento de justiça que deve se estender a todos que acreditam nela.

Este texto, que tem como proposta proporcionar reflexões sobre o papel do direito dentro das demandas das comunidades tradicionais, é também uma despedida e um agradecimento. Kabiesi ooo, Oke Arô! Adupé Iyá!

\section{Referências Bibliográficas}

do BRASIL, Constituição Federal. Constituição da República Federativa do Brasil de 1988. Recuperado de http://www.ritmodeestudos.com.br, 2010.

DAMASIO, Ana C. S.; AHUALLI, Iyaromi F. Às Mais Velhas. In: BRASÍLIA, Revista Calundu, v.2n.2, 2018 (http://periodicos.unb.br/index.php/revistacalundu/article/view/15261).

GUIMARÃES, Andréa Letícia Carvalho. "Os Terreiros como Espaço da Diferença: Análise sobre as Intervenções" do Estado nas Comunidades Tradicionais de Matriz Africana. In: Revista Calundu, 2(1), 2018. Disponível em: https://doi.org/10.26512/revistacalundu.v2i1.9601

“ "ĖTÓ FÚN ÀWÒN TÓ YÀTÒ”: análise do I Plano nacional de inclusão dos povos e comunidades tradicionais de matriz africana a partir dos processos de reconstrução da identidade do sujeito constitucional, 2014.

MALYSSE, Stéphane. "Antropologia da morte: um fato social fatal." ___ (Org.). In: Opus Corpus. Antropologia das aparências corporais. Disponível em< http://incubadora. fapesp. br/sites/opuscorpus/portugues/t11/artigo. html>. Acesso em 1 (2020).

NOGUEIRA, Nilo. S., \& NOGUEIRA, Guilherme. D. “A Questão da Laicidade do Estado Brasileiro e as Religiões Afro-brasileiras". In: Revista Calundu, 2(1). 2018. Disponível em: https://doi.org/10.26512/revistacalundu.v2i1.9544

OLIVEIRA, Ariadne Moreira Basílio de. Religiões afro-brasileiras e o racismo: contribuição para a categorização do racismo religioso. (dissertação) 2017.

. (2018). "Um Panorama das Violações e Discriminações às Religiões Afrobrasileiras como Expressão do Racismo Religioso". In: Revista Calundu, 2(1). Disponível em: https://doi.org/10.26512/revistacalundu.v2i1.9545 
PARÉS, Luis Nicolau. O Rei, o Pai e a morte: a religião vodum na antiga costa dos escravos na Africa Ocidental. Editora Companhia das Letras, 2016.

SARLET, Ingo Wolfgang. Dignidade da Pessoa Humana e Direitos Fundamentais na Constituição Federal de 1988. 5. ed. Porto Alegre: Livraria do Advogado, 2007. p.62.(2)

SIMIÃO, Daniel S. "Sensibilidades jurídicas e respeito às diferenças: cultura, controle e negociação de sentidos em práticas judiciais no Brasil e em Timor-Leste." Anuário Antropológico II (2014): 237-260.Tartuce, Flávio. Manual de direito civil 6.ed. Método, 2018.

Recebido em: 10/05/2020

Aceito em: 14/05/2020 